\title{
PROJETO E IMPLEMENTAÇÃO DE UM SISTEMA DE SINALIZAÇÃO PARA O INSTITUTO FEDERAL DA PARAÍBA
}

\section{PROJECT AND IMPLEMENTATION PLAN OF A SIGNAGE SYSTEM FOR INSTITUTO FEDERAL DA PARAÍBA}

\author{
Luciana Mendonça Dinoá Pereira ${ }^{1}$, M.Sc. \\ Daniel de Sousa Andrade², Bel. Esp. \\ Handersson Mendes da Costa ${ }^{3}$, Tecg. \\ Adriana Travassos Duarte Jácome ${ }^{4}$, Tecg. \\ Elaine Feitosa da Silva ${ }^{5}$ \\ (1) $I F P B$ \\ e-mail: ludinoa@hotmail.com \\ (2) $I F P B$ \\ e-mail: danielmental@yahoo.com.br \\ (3) $I F P B$ \\ e-mail: handersson.me@gmail.com
}

(4) IFPB

e-mail: atravass@gmail.com

(5) $I F P B$

e-mail: helainefs@gmail.com

Sistema, sinalização, projeto

Planejar a sinalização do ambiente é uma tarefa essencial, pois contribui para a orientação das pessoas. O artigo aborda o desenvolvimento de um sistema de sinalização para o Instituto Federal da Paraíba (IFPB). As estruturas de sinalização foram criadas segundo recomendações ergonômicas, definindo-se um padrão visual e todas as especificações, para facilitar a produção e instalação.

System, signage, design

A signage system is essential in any place to help guide people. This article discusses the development of a signage system for Instituto Federal da Paraíba (IFPB). The signage structures were created according to ergonomic recommendations defining a visual standard and specifications, to facilitate their production and installation. 


\section{$16^{\circ}$ \\ ERGODESIGN USIHC CINAHPA}

CINAHPA

\section{Introdução}

As pessoas têm se tornado estranhas, em ambientes cada vez mais complexos, com o crescimento das cidades e o aumento da mobilidade, o que se tornou evidente nas instituições de ensino. Até a Segunda Guerra Mundial, as universidades mantinham uma estrutura padrão, formadas por edifícios clássicos simétricos, com entradas bem marcadas, como as Universidades de Harvard, Oxford e Sorbonne. Havia uma necessidade mínima de sinalização que orientasse as pessoas, pois poucas tinham mais de cinco mil habitantes. As universidades se expandiram e projetar a sinalização, de acordo com as particularidades locais, tornou-se urgente.

A sinalização ajuda as pessoas a se deslocar com eficiência, encontrar um caminho, levar outros a saberem onde alguém poderá ser encontrado, evitar riscos ou sair em segurança de um lugar em situações de perigo. Apesar dessa importância, verificou-se a inexistência de um sistema de sinalização nos campi do IFPB. Os sinais de identificação dos ambientes são improvisados e insuficientes, feitos com o auxílio de servidores, devido ao caráter emergencial do problema, reduzindo as atividades de sinalização a uma simples colocação de placas.

Assim, esse artigo apresenta o desenvolvimento de um sistema de sinalização para o IFPB, configurado inicialmente para sede da sua Reitoria, a Casa Rosada. O sistema servirá como base para que a sinalização seja implementada em todos os campi do Instituto. Foram desenvolvidos e especificados todos os elementos de sinalização necessários, sempre levando em consideração as necessidades dos usuários.

Um projeto como este será refletido no cotidiano dos usuários, tornando simples e prático os seus deslocamentos e fazendo com que se sintam seguros e confortáveis. $16^{\circ}$ Ergodesign - Congresso Internacional de Ergonomia e Usabilidade de Interfaces Humano Tecnológica: Produto, Informações Ambientes Construídos e Transporte

$16^{\circ}$ USIHC - Congresso Internacional de Ergonomia e Usabilidade de Interfaces Humano Computador

CINAHPA | 2017 - Congresso Internacional de Ambientes Hipermídia para Aprendizagem.

\section{A importância da sinalização no espaço público}

As instituições de ensino em geral constituem-se em espaços públicos complexos e os projetos de sinalização tornaram-se cada vez mais necessários. De acordo com Berger (2009), duas mudanças foram responsáveis pelo aumento dessa necessidade. A primeira foi a rápida expansão iniciada na década de 50, onde os campi tornaramse minicidades, com uma grande variedade de espaços, e a segunda foi o crescimento do movimento da arquitetura moderna que quebrou a estrutura tradicional das universidades, substituindo-a por outra na qual os edifícios pareciam ser exatamente iguais, sem a clara localização das entradas e portões e com layouts assimétricos. Este precedente foi estabelecido pelo Instituto de Tecnologia de Illinois. Os campi perderam a sua estrutura básica de navegação, criando assim a necessidade de sinais, placas, mapas e outros elementos informativos.

Ambientes abertos ao público recebem uma grande variedade de pessoas e, por serem frequentados por grupos diversos de uma sociedade heterogênea, requerem que a sinalização auxilie no seu compartilhamento. Quanto mais complexo for o ambiente, maior será a necessidade de se planejar o fluxo de informação contido nele. Para GOMES FILHO (2000, p. 209), "a importância desses sistemas de sinalização é, em muitos casos, crucial, sobretudo nos espaços de grande concentração de pessoas."

Segundo Smitshuijzen (2007) navegar em ambientes sem placas de sinalização seria como assistir ao noticiário com o som desligado. A missão das instituições de ensino é primar por uma educação de qualidade, formando cidadãos éticos, solidários e competentes e esta filosofia pode ser refletida visualmente em soluções eficientes de sinalização no ambiente construído.

\section{Sistemas de sinalização}

Para Calori (2007), o propósito principal dos 
$16^{\circ}$ Ergodesign - Congresso Internacional de Ergonomia e Usabilidade de Interfaces Humano Tecnológica: Produto, Informações Ambientes Construídos e Transporte

$16^{\circ}$ USIHC - Congresso Internacional de Ergonomia e Usabilidade de Interfaces Humano Computador CINAHPA

CINAHPA | 2017 - Congresso Internacional de Ambientes Hipermídia para Aprendizagem.

sistemas de sinalização é comunicar uma informação que será transmitida através de gráficos, exibidos em equipamentos. Daí, chegou à conclusão que um sistema de sinalização é composto de três componentes que se interrelacionam: o conteúdo da informação, os gráficos e os equipamentos.

\subsection{Conteúdo da informação}

O conteúdo da informação se refere a mensagem que a sinalização comunica e onde estará localizada no ambiente. Antes de se projetar, é preciso analisar a planta-baixa do lugar, os caminhos de circulação, os pontos de decisão, ou seja, os lugares onde os usuários precisam definir que direção devem seguir, e as informações que devem ser transmitidas em cada lugar. Enfim, tudo necessário para se mapear a localização de cada elemento de sinalização, os tipos e quantidade de informação que devem transmitir.

A importância do conteúdo da informação é destacada por Gibson (2009), que diz que é a voz do edifício, revelando os caminhos e destinos do ambiente, as regras que determinam o seu uso e as atividades que estão acontecendo.

Sistemas de sinalização podem possuir diversas informações e assim constituem-se num conjunto de elementos com variadas funções. Alguns autores utilizam-se de termos diferentes para se referir a essas funções. Para Gibson (2009) e Smitshuijzen (2007) existem quatro funções básicas que são: identificar, direcionar, orientar e regulamentar. Essas funções foram as adotadas nesse estudo.

Os elementos de sinalização de identificação confirmam que você chegou ao local procurado. Os direcionais ajudam as pessoas a decidir qual direção devem seguir. Os de orientação oferecem uma visão geral do ambiente na forma de mapas e diretórios e os de regulamentação descrevem os avisos e as restrições.

De acordo com Calori (2007), as mensagens transmitidas pela sinalização devem ser consistentes e concisas, pois esses adjetivos são essenciais para uma comunicação clara.

Mensagens consistentes são a chave para manter o 'rastro' da informação. Uma vez que o nome do destino é determinado, este deve ser usado em todos os sinais que a ele se referem. Mensagens concisas ajudam a economizar espaço e evitar excesso de informação. Conclui-se que a informação é a essência funcional de um projeto de sinalização.

\subsection{Gráficos}

No desenvolvimento dos gráficos de um sistema de sinalização, manipula-se dispositivos de comunicação visual como a tipografia, cores, mapas, pictogramas e setas.

A tipografia é um elemento essencial porque a informação é transmitida através das palavras. Segundo Gibson (2009), deve-se levar em consideração diversos fatores para a escolha da tipografia ideal como: a distância de visualização, a velocidade de observação, os objetivos da mensagem, o perfil dos usuários e as características do ambiente.

Para Calori (2007), existem três principais fatores para a escolha da tipografia como: adequação formal, longevidade estilística e legibilidade. A adequação formal refere-se à compatibilidade visual do tipo com as características do ambiente. A longevidade estilística refere-se à utilização de uma tipografia que possa sobreviver ao tempo e a legibilidade refere-se a fácil identificação individual dos caracteres, o que difere da leiturabilidade que diz respeito a compreensão intelectual, ou seja, como lemos a informação. Bastos (2004), recomenda a utilização de uma tipografia com desenho robusto e sem serifa, nem muito espaçada a ponto de parecerem letras soltas e desconexas, nem muito apertada, pois tornam-se irreconhecíveis e ilegíveis.

Em relação às cores, o seu papel na sinalização é contrastar ou harmonizar com o ambiente, aumentar o significado das mensagens, distinguir uma mensagem da outra ou apenas ter apelo 


\section{$16^{\circ}$ \\ ERGODESIGN USIHC CINAHPA}

estético. Além disso, a cor tem a capacidade de fornecer identidade a um determinado local e conectar emocionalmente as pessoas a ele. Segundo D'Agostini e Gomes (2010), as cores também podem determinar setores, alertar sobre procedimentos, restringir ações e auxiliar na tomada de decisão. Assim, uma cor pode ser um elemento organizador central de um sistema de sinalização.

Os mapas, pictogramas e setas são dispositivos gráficos que comunicam a informação através de figuras. Para Gibson (2009), em lugares públicos são essenciais, pois tornam-se um idioma comum a todos. Enquanto os pictogramas e setas fornecem informação rápida, os mapas são imagens visuais mais complexas para explicar o lugar aos usuários, descrevendo o arranjo dos espaços. São, portanto, de igual importância aos demais elementos do projeto.

\subsection{Equipamentos}

É a parte tangível do sistema, tridimensional. É essa tridimensionalidade intrínseca que faz da sinalização um excelente desafio de design. Engloba o vocabulário de formas, estruturas, materiais, acabamento, montagem e iluminação. Esses equipamentos podem ser montados no chão, pendentes, projetados ou nivelados à parede.

De acordo com Smitshuijzen (2007), os elementos de sinalização são praticamente feitos de todos os tipos de materiais e as formas pelas quais os gráficos são aplicados também são muito variadas. É quase impossível fornecer uma visão geral do que existe disponível no mercado para a produção da sinalização.

Diante do exposto, percebe-se que os três componentes do sistema de sinalização abordados se complementam. Um sistema influencia o outro e para que todos funcionem de maneira correta, é importante que possuam coerência e unidade visual. $16^{\circ}$ Ergodesign - Congresso Internacional de Ergonomia e Usabilidade de Interfaces Humano Tecnológica: Produto, Informações Ambientes Construídos e Transporte

$16^{\circ}$ USIHC - Congresso Internacional de Ergonomia e Usabilidade de Interfaces Humano Computador

CINAHPA | 2017 - Congresso Internacional de Ambientes Hipermídia para Aprendizagem.

\section{Metodologia}

O método utilizado no projeto foi o proposto por CALORI (2007) que divide o projeto em três grandes grupos: Pré-Projeto; Projeto e Pós-Projeto, subdivididos em sete fases (Tabela 1).

\begin{tabular}{|l|l|}
\hline \multirow{2}{*}{ Etapas } & Fases \\
\hline Pré-projeto & Coleta de informações \\
\hline \multirow{2}{*}{ Projeto } & Desenho esquemático \\
\cline { 2 - 2 } & Desenvolvimento \\
\cline { 2 - 2 } & Documentação \\
\hline \multirow{2}{*}{ Pós-projeto } & Orçamento \\
\cline { 2 - 2 } & $\begin{array}{l}\text { Acompanhamento da fabricação } \\
\text { e instalação }\end{array}$ \\
\cline { 2 - 2 } & Avaliação \\
\hline
\end{tabular}

Tabela 1: Etapas do Projeto de Sinalização. Fonte: adaptado de CALORI (2007. p.16)

A etapa do Pré-Projeto corresponde a fase de coleta de informações, onde foram levantados dados do ambiente e dos usuários. Foram digitalizadas as plantas-baixas, realizadas fotografias e analisadas as vias de circulação, pontos de decisão e a identidade visual da Instituição. Também foram aplicados questionários com os usuários, buscando traçar o seu perfil, o que foi fundamental para a elaboração da proposta.

A etapa do Projeto engloba o Desenho Esquemático, Desenvolvimento e Documentação. Foram determinadas a localização, função, vocabulário e hierarquia das informações. Na parte gráfica, foram analisadas as opções de tipografia, pictogramas e cores, explorando o aspecto visual do projeto. Quanto à parte física, foram observadas as opções de materiais, montagem e acabamentos. A solução aprovada foi detalhada, refinando-se a tipografia, pictogramas e cores. Também foram avaliadas as distâncias de visualização das informações, a espessura das linhas dos símbolos, e os contrastes, adequando toda a parte gráfica a normas geométricas e recomendações ergonômicas. Ainda foram feitos os desenhos 


\section{$16^{\circ}$ \\ ERGODESIGN USIHC CINAHPA}

$16^{\circ}$ Ergodesign - Congresso Internacional de Ergonomia e Usabilidade de Interfaces Humano Tecnológica: Produto, Informações Ambientes Construídos e Transporte

$16^{\circ}$ USIHC - Congresso Internacional de Ergonomia e Usabilidade de Interfaces Humano Computador

CINAHPA | 2017 - Congresso Internacional de Ambientes Hipermídia para Aprendizagem. técnicos, especificando os elementos de sinalização para viabilizar a sua produção e instalação.

A última etapa, Pós-Projeto, envolveu questões referentes ao orçamento, fabricação e instalação dos elementos de sinalização desenvolvidos.

\section{Problemas existentes}

Um sistema de sinalização é composto por um conjunto de placas, com funções diferentes, que estão interconectadas, de forma a garantir que os usuários possam se orientar e navegar dentro do espaço sem dificuldades. A partir do levantamento de dados acerca do ambiente percebeu-se que os campi do IFPB, assim como todas as edificações a ele atreladas, que abrigam atividades

administrativas, como é o caso da casa Rosada, não apresentam um sistema dessa natureza. Verificouse a utilização de placas improvisadas, com o uso de materiais inapropriados, desenvolvidas sem critérios gráficos, mal localizadas e em quantidade insuficiente, o que faz com que seus usuários sintam-se confusos e perdidos.

A entrada da Casa Rosada não possui nenhuma identificação da Instituição. Assim, os usuários precisam pedir informação ainda na rua para confirmar se estão acessando o local correto (Figura 1).

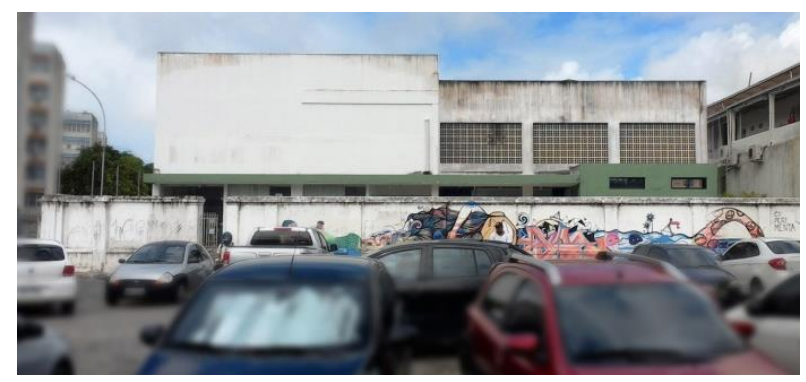

Figura 1 - Fachada com acesso principal sem identificação da Instituição.

No interior da edificação, não existem placas direcionais que indiquem o caminho para se chegar aos ambientes. Nas portas das salas, encontra-se uma sinalização frágil, improvisada em folhas de papel, sem unidade visual, devido ao uso de tipografias e tamanhos diferentes. Nos banheiros, há apenas o uso de pictogramas para a identificação do ambiente, no entanto o símbolo utilizado não é de fácil reconhecimento pelos usuários (Figura 2).

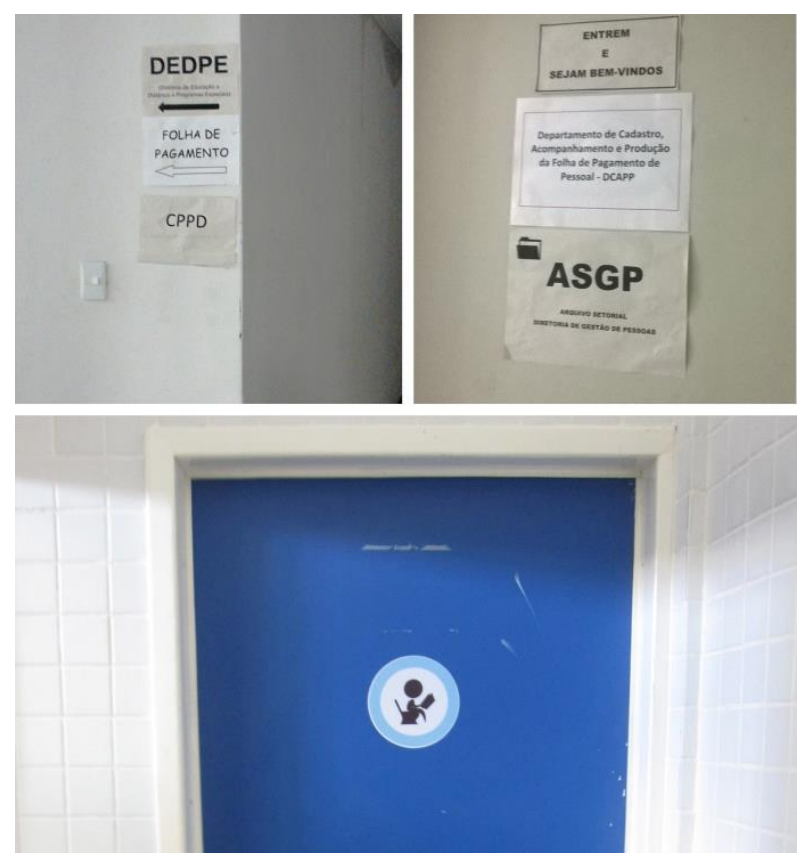

Figura 2 - Utilização de placas improvisadas em papel causando desvalorização visual do ambiente, e pictograma de banheiro de difícil compreensão.

Por se tratar de uma edificação composta por dois blocos, com dois pavimentos, sem mapas ou diretórios, os usuários não sabem como os ambientes estão dispostos nesse espaço e precisam sempre pedir ajudar para chegar ao local procurado.

O que se percebe é que a sinalização interna foi pensada com o auxílio dos próprios servidores que se dispuseram a ajudar, devido ao caráter emergencial do problema, mesmo sem ter conhecimentos específicos para desenvolver tal projeto. Sinalizar um local é bem mais do que colocar placas nas paredes e portas, prática comum que se repete na sinalização da Instituição. É indispensável um planejamento desde a fase inicial

\section{Realização:}




\section{$16^{\circ}$ \\ ERGODESIGN USIHC CINAHPA}

do projeto, de forma que sejam analisados o ambiente, os fluxos e os usuários, bem como todas as informações que serão transmitidas e os suportes físicos que vão exibi-las.

Além disso, um sistema de sinalização deve estar de acordo com o disposto na ABNT NBR 9050/15, que estabelece critérios e parâmetros técnicos que devem ser adotados para garantir a sua total acessibilidade e compreensão por todos os tipos de usuários. No entanto, face ao improviso da sinalização existente, tais parâmetros não foram abordados.

Por não dispor de um Manual de Sinalização na Instituição, sempre há dificuldade na elaboração de placas de forma padronizada, tanto no interior dos prédios, como também nas áreas externas, como acessos e estacionamentos. O uso aleatório desses elementos contribui para uma mensagem dispersa, não objetiva e embaraçosa.

Após a observação dos problemas constatados, vale citar Smitshuijzen (2007), o qual enfatiza que decisões de última hora sobre sinalização, as vezes até mesmo tomadas em pânico, não são incomuns. Claramente não é a condição ideal para a criação da espaços acessíveis e confortáveis.

\section{Desenvolvimento do sistema de sinalização}

Após a coleta de informações acerca dos ambientes, foram aplicados questionários junto aos usuários com a finalidade de definir o perfil e as necessidades. Verificou-se que a maior parte dos entrevistados possui mais de 40 anos, é do sexo masculino, com pós-graduação e utiliza o carro como meio de transporte. Em relação à sinalização existente, $81 \%$ dos entrevistados precisaram pedir informação para se locomover pela edificação até se familiarizar com o lugar. Diante de todas essas informações e da definição de um partido a ser adotado, iniciou-se o desenvolvimento do projeto.

\subsection{Mensagens}

Conhecendo-se o perfil dos usuários, foi analisado $16^{\circ}$ Ergodesign - Congresso Internacional de Ergonomia e Usabilidade de Interfaces Humano Tecnológica: Produto, Informações Ambientes Construídos e Transporte

$16^{\circ}$ USIHC - Congresso Internacional de Ergonomia e Usabilidade de Interfaces Humano Computador

CINAHPA | 2017 - Congresso Internacional de Ambientes Hipermídia para Aprendizagem.

e traçado o fluxo na Casa Rosada, buscando entender a lógica de funcionamento do lugar. Em seguida, foram definidos os tipos de sinalização necessárias e as mensagens que precisavam ser transmitidas em cada lugar. Assim foi realizada a marcação da sua localização nas plantas-baixas do térreo e primeiro andar (Figuras 3, 4 e 5).

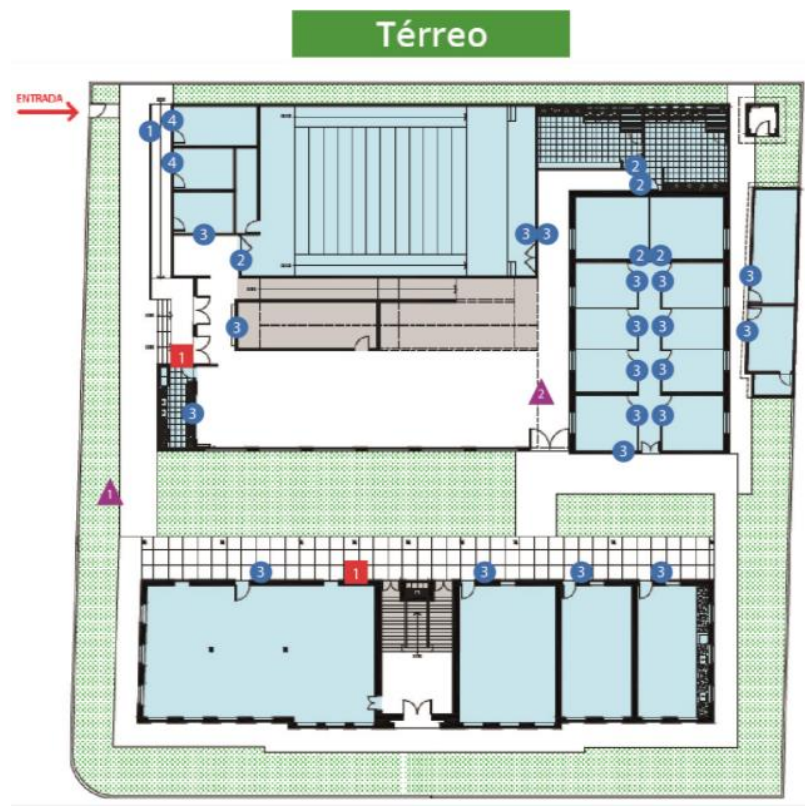

Figura 3 - Marcação dos tipos de sinalização, no térreo da Casa Rosada. 

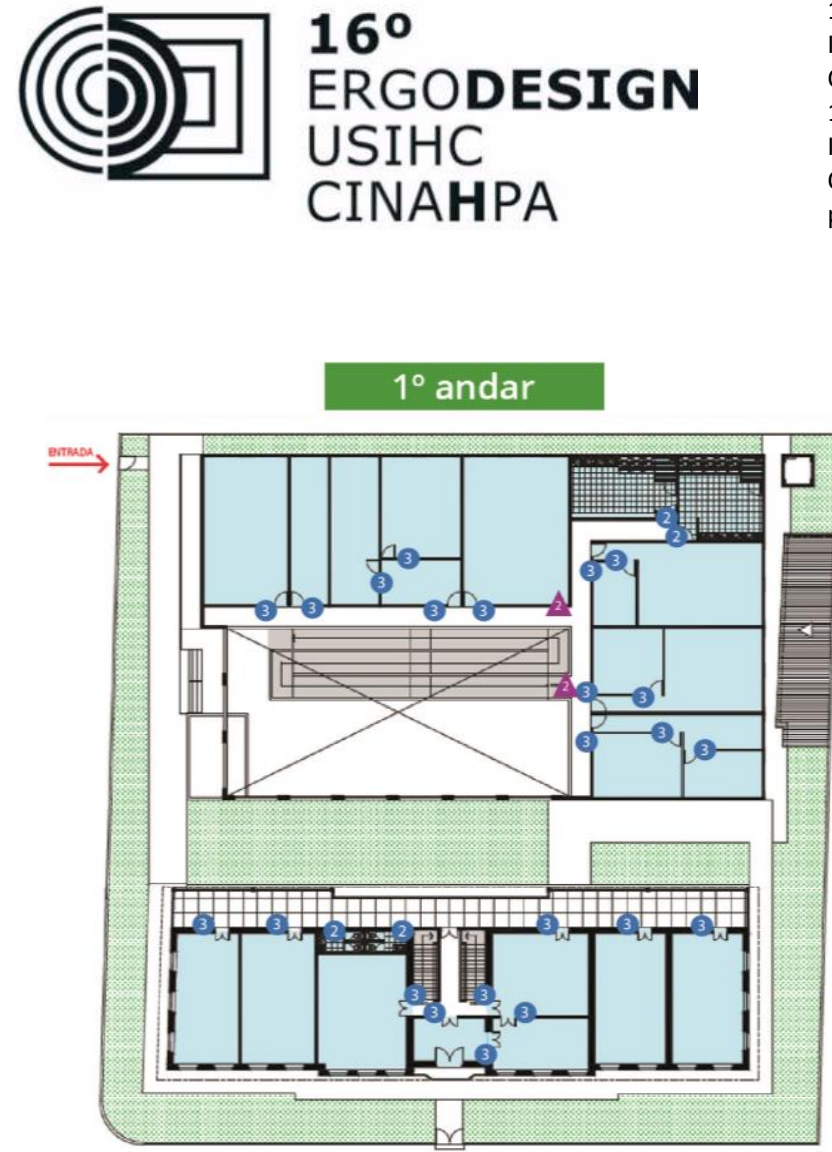

Figura 4 - Marcação dos tipos de sinalização, no $1^{\circ}$ pavimento da Casa Rosada.

\begin{tabular}{|c|c|c|c|c|}
\hline Tipos de sinais & Funçáo & Tipo & Localizaçâo & Quantidade \\
\hline \multirow[t]{4}{*}{ Identificativos } & $\begin{array}{l}\text { Identificativa do local } \\
\text { da Sede da Reitoria }\end{array}$ & (1) & Externa & 1 \\
\hline & Identificativa dos espaços & (2) & Interna & 9 \\
\hline & Identificativa dos espaços & (3) & Interna & 43 \\
\hline & Identificativa dos espaços & (4) & Interna & 2 \\
\hline \multirow[t]{3}{*}{ Direcionais } & \multirow[t]{3}{*}{ Direcionais de ambientes } & $\boldsymbol{\Lambda}$ & Externa & 1 \\
\hline & & 2 & Interna & 2 \\
\hline & & B & Interna & 1 \\
\hline Orientativos & Diretórios & 1 & Intema & 1 \\
\hline
\end{tabular}

Figura 5 - Legenda com os sinais criados para identificar os tipos de placas presentes da sinalização.

Os setores que funcionam na Casa Rosada são, em sua maioria, conhecidos através de siglas, porém de acordo com o resultado dos questionários aplicados, apenas aqueles que trabalham na edificação conhecem os significados. $\mathrm{O}$ demais usuário tem dificuldade de encontrar os ambientes procurados pois não estão familiarizados com essas $16^{\circ}$ Ergodesign - Congresso Internacional de Ergonomia e Usabilidade de Interfaces Humano Tecnológica: Produto, Informações Ambientes Construídos e Transporte

$16^{\circ}$ USIHC - Congresso Internacional de Ergonomia e Usabilidade de Interfaces Humano Computador

CINAHPA | 2017 - Congresso Internacional de Ambientes Hipermídia para Aprendizagem.

siglas. Assim, optou-se por escrever nas placas identificativas a sigla correspondente ao ambiente e o nome por extenso, facilitando a identificação por todas as pessoas que frequentam o lugar.

Com isso, as ideias foram evoluindo e o projeto esquemático foi desenvolvido. A primeira ideia teve como principal referência a identidade visual do Instituto, utilizando-se a cor e a tipografia institucionais. Este conceito evoluiu até chegar na solução final aplicada em todas as estruturas físicas do sistema de sinalização: placas identificativas de ambientes, placas direcionais internas, suspensas e planas, e externas (totem), e placas orientativas (Figura 6). 


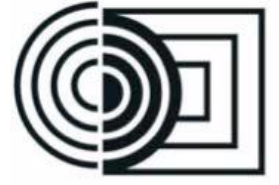

$16^{\circ}$

ERGODESIGN USIHC CINAHPA
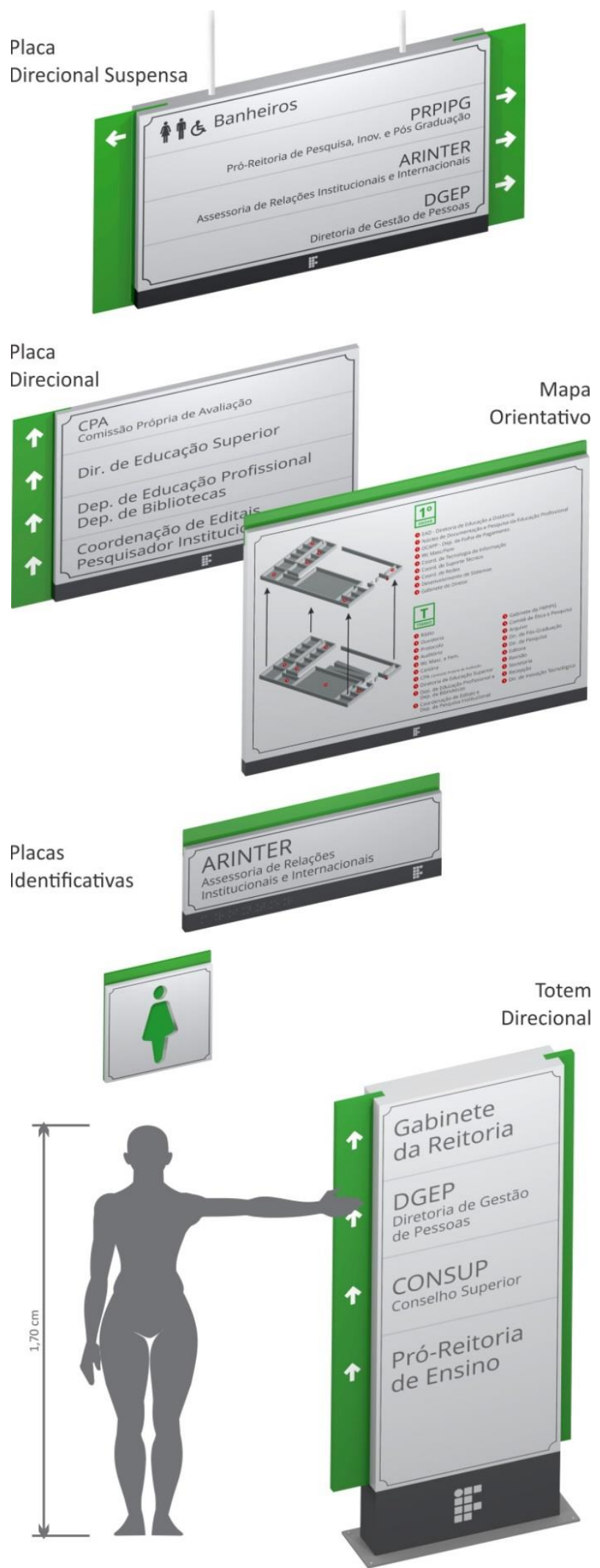

$16^{\circ}$ Ergodesign - Congresso Internacional de Ergonomia e Usabilidade de Interfaces Humano Tecnológica: Produto, Informações Ambientes Construídos e Transporte

$16^{\circ}$ USIHC - Congresso Internacional de Ergonomia e Usabilidade de Interfaces Humano Computador

CINAHPA | 2017 - Congresso Internacional de Ambientes Hipermídia para Aprendizagem.

Figura 6 - As novas estruturas de sinalização. Placas identificativas, totens direcionais, placas direcionais aéreas e mapas de localização.

\subsection{Sinalização acessível}

Para tornar o sistema de sinalização acessível a todos os tipos de usuários, dentre eles deficientes visuais e cadeirantes, na fase de desenvolvimento do projeto, as estruturas foram criadas seguindo as recomendações da ABNT NBR 9050/15, que atenta para questões relativas a dimensão, posicionamento, altura de instalação, inserção de informações visuais e táteis, materiais empregados, contraste e distâncias de visualização.

Seguindo estas orientações, o projeto buscou incluir o texto em braile em todas as placas de identificação dos ambientes, adequando de forma harmônica a informação textual (visual) com a informação em Braille (tátil), sem criar poluição visual e nem onerar o custo de produção das peças. A solução encontrada foi a de incluir uma faixa cinza escura na base das placas identificativas de ambiente, onde foram aplicados o relevo em Braille composto por esferas de aço inox de $\varnothing 2 \mathrm{~mm}$, fixadas por aplicador de pressão manual e pintadas na mesma cor cinza escura da faixa. Essas placas foram colocadas a uma altura de $1.50 \mathrm{~m}$ do chão, na parede adjacente às portas, ao mesmo lado das maçanetas, conforme estabelecido pela NBR $9050 / 15$, garantindo acessibilidade às pessoas com deficiência visual. Os arranjos geométricos dos pontos em Braille obedecem aos parâmetros ergonômicos da digital humana também em conformidade com a NBR 9050/15. (Figura 7).

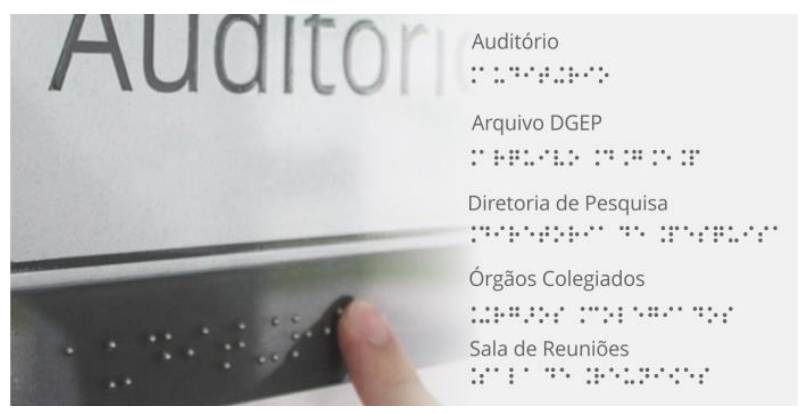


$16^{\circ}$ Ergodesign - Congresso Internacional de Ergonomia e Usabilidade de Interfaces Humano Tecnológica: Produto, Informações Ambientes Construídos e Transporte

$16^{\circ}$ USIHC - Congresso Internacional de Ergonomia e Usabilidade de Interfaces Humano Computador CINAHPA

CINAHPA | 2017 - Congresso Internacional de Ambientes Hipermídia para Aprendizagem.

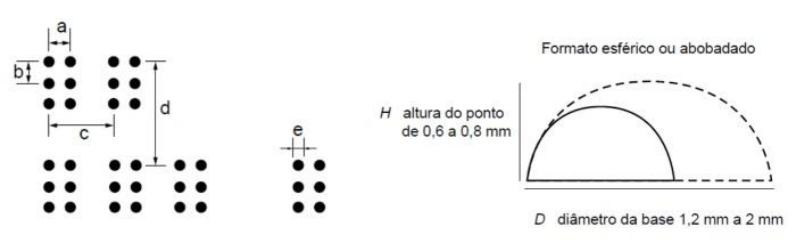

\begin{tabular}{c|c|c|c|c|c}
\hline a & b & c & d & $\begin{array}{c}\text { Diâmetro do } \\
\text { ponto } \\
\boldsymbol{e}=\mathbf{D}\end{array}$ & $\begin{array}{c}\text { Altura do } \\
\text { ponto } \mathbf{H}\end{array}$ \\
\hline 2,7 & 2,7 & 6,6 & 10,8 & de $1,2 \mathrm{a} 2,0$ & de 0,6 a 0,8 \\
\hline
\end{tabular}

Figura 7 - Detalhe da aplicação do Braille e dos arranjos geométricos dos pontos. Fonte: Adaptado da ABNT NBR 9050/15 (2015, p. 37).

Desta forma, foi possível aliar a inclusão da informação tátil, valorizando a estética da peça, sem a necessidade de produção de estruturas separadas do sistema, que ocasionariam maior custo de produção.

Outro ponto considerado no projeto foi o percentual de usuários que possuem deficiência visual parcial e que não foram alfabetizados no sistema Braille. Para estes usuários é possível sentir o relevo das letras com o toque, pois os caracteres foram recortados digitalmente em vinil adesivo de maior gramatura e receberam aplicação de verniz transparente ultravioleta. $O$ verniz tem a função de aumentar a vida útil contra a ação do tempo, evitando descolamento do adesivo e cria volume adicional nos limites deste

Para as placas identificativas dos banheiros foi implementada uma solução que visa a acessibilidade via tato. As placas em Policloreto de Vinil expandido (PVC) foram recortadas digitalmente no formato do pictograma correspondente ao banheiro masculino, ,feminino e banheiro acessível.

\subsection{Aplicação dos gráficos}

$\mathrm{Na}$ fase de geração dos conceitos, um dos maiores desafios foi encontrar uma solução formal que possuísse boa integração visual com as características particulares do ambiente a ser sinalizado. A edificação sede da reitoria, Casa Rosada, possui características tradicionais da arquitetura Art Decó praticadas no século passado

(Figura 8).

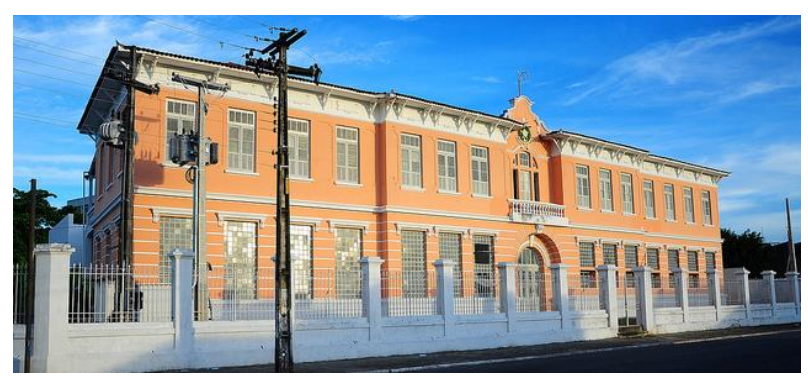

Figura 8 - Fachada Casa Rosada, arquitetura Art Decó

Assim, a solução definitiva foi encontrada ao se utilizar linhas mais retas no desenho das placas, além de implementar uma solução gráfica que consiste no emprego de uma moldura ao redor da informação, tendo como base traços presentes na fachada da edificação.

Também foram levados em consideração no projeto, fundamentos da ergonomia informacional, na composição gráfica, com o objetivo de enviar a informação correta de forma eficaz e eficiente respeitando a diversidade dos usuários, em termos de habilidades e limitações.

As placas de sinalização foram projetadas para serem também aplicadas em todos os campi do IFPB. Desse modo, em relação as cores empregadas, optou-se por utilizar tons de cinza, um mais claro e outro mais escuro, por se tratar de uma cor neutra que se adaptaria bem aos diferentes tipos de arquitetura desses lugares, além de permitir o uso de materiais de alta durabilidade, como o ACM (Alumínio Composto) cinza. Sob o tom mais claro, estão dispostas as informações mais relevantes; já no tom escuro, apenas o símbolo do IF, por ser uma informação secundária, e o Braille, conforme já especificado. O verde institucional também foi empregado, porém numa proporção reduzida.

A escolha da tipografia foi baseada na família tipográfica institucional, especificada no Manual de Aplicação da Marca, da Rede Federal de Educação Profissional, Científica e Tecnológica (2015). Considerou-se a nova versão da identidade
Realização:

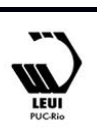




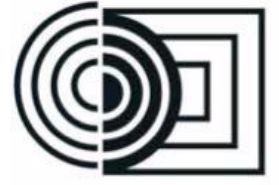

ERGODESIGN USIHC CINAHPA $16^{\circ}$ Ergodesign - Congresso Internacional de Ergonomia e Usabilidade de Interfaces Humano Tecnológica: Produto, Informações Ambientes Construídos e Transporte

$16^{\circ}$ USIHC - Congresso Internacional de Ergonomia e Usabilidade de Interfaces Humano Computador

CINAHPA | 2017 - Congresso Internacional de Ambientes Hipermídia para Aprendizagem. visual do IF, apresentada no ano de 2015.

Também foram criados os pictogramas a serem utilizados e aplicados nos elementos de sinalização. Foi levada em consideração a existência de uma identidade de marca, utilizada pela Instituição. A identidade de marca norteou toda a criação dos pictogramas. Foi utilizado um conceito baseado nas formas de círculo e quadrados de bordas arredondadas, que compõem a marca, na construção dos desenhos. Tais artifícios foram utilizados para manter a identidade do IFPB em todo o projeto de sinalização em consonância com o ambiente e com a filosofia da Instituição (Figura 9).

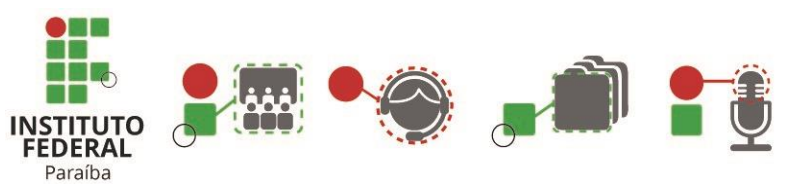

Figura 9 - Símbolo da assinatura visual do IFPB que serviu como conceito para criação dos pictogramas com quadrados de bordas arredondadas e círculos

O desenho dos pictogramas foi desenvolvido em consonância com critérios ergonômicos abordados por Iida (2005), como a utilização de contornos fortes e bem definidos, a simplicidade e estabilidade das formas, com poucos detalhes, e a simetria, que gerou figuras equilibradas. Tudo isso visando garantir legibilidade e, consequentemente, a fácil codificação da mensagem e condução do público (Figura 10). Após esse processo de criação, elaborou-se um questionário, com três opções de pictogramas para cada ambiente, e foi aplicado junto aos servidores e usuários da Casa Rosada, professores e estudantes do curso de Design Gráfico do IFPB. Pôde-se, então, definir as alternativas mais apropriadas de acordo com a avaliação das pessoas e aplicá-las nos elementos de sinalização (Figura 11 e 12).

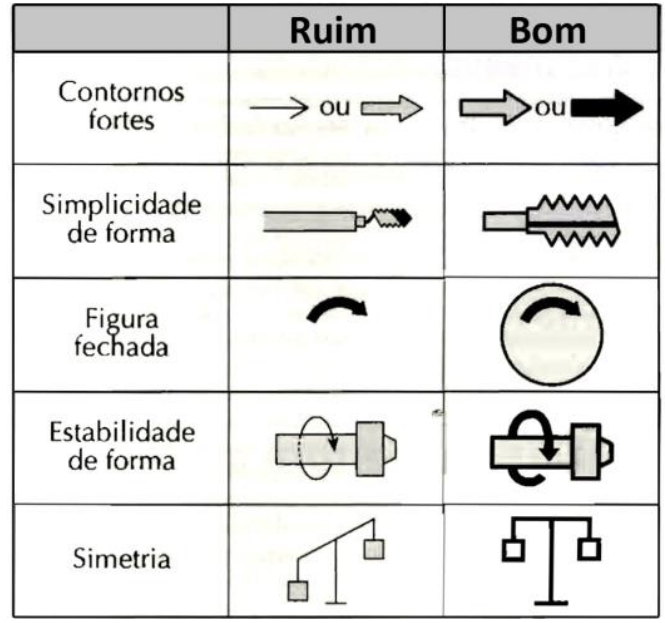

Figura 10 - Critérios ergonômicos aplicados aos pictogramas selecionados. Fonte: Iida, (2005, p.293).

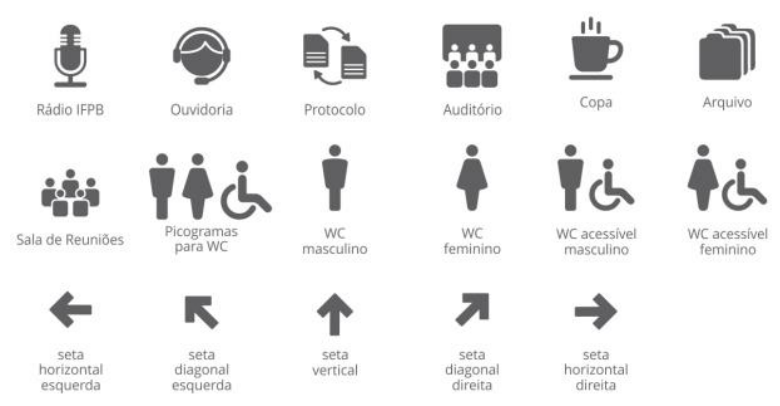

Figura 11 - Pictogramas selecionados após teste de reconhecimento junto aos usuários.
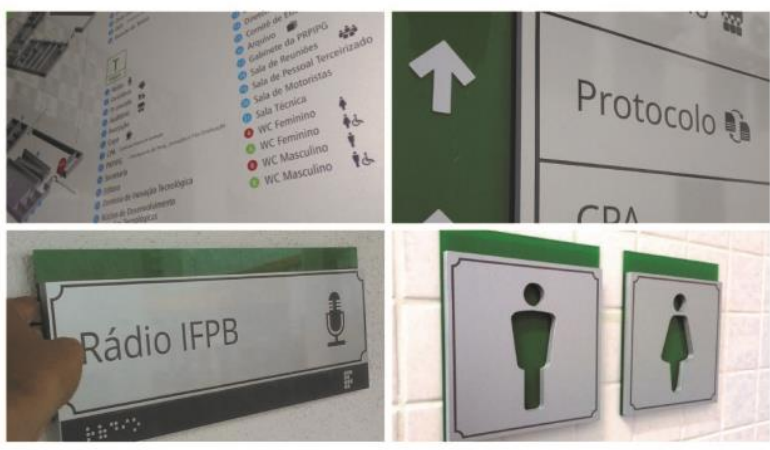

Figura 12 - Placas com a aplicação dos pictogramas.

Para complementar as informações de orientação 


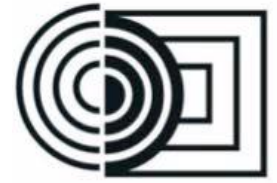

ERGODESIGN USIHC CINAHPA $16^{\circ}$ Ergodesign - Congresso Internacional de Ergonomia e Usabilidade de Interfaces Humano Tecnológica: Produto, Informações Ambientes Construídos e Transporte

$16^{\circ}$ USIHC - Congresso Internacional de Ergonomia e Usabilidade de Interfaces Humano Computador

CINAHPA | 2017 - Congresso Internacional de Ambientes Hipermídia para Aprendizagem. dos usuários, foram criados mapas para serem aplicados nos diretórios. Visando um melhor. entendimento por parte dos usuários, foram desenhadas plantas tridimensionais da edificação, mostrando a localização de todos os seus ambientes, bem como toda a circulação e corredores de acessos a esses locais. Optou-se pelo desenho de plantas perspectivadas, pois a utilização de esquemas em três dimensões facilita a orientação, sobretudo de pessoas que não são familiarizadas com o desenho de plantas baixas. Através desses mapas, o usuário pode ver o lugar exato em que ele se encontra e como se deslocar até o ambiente procurado (Figura 13).

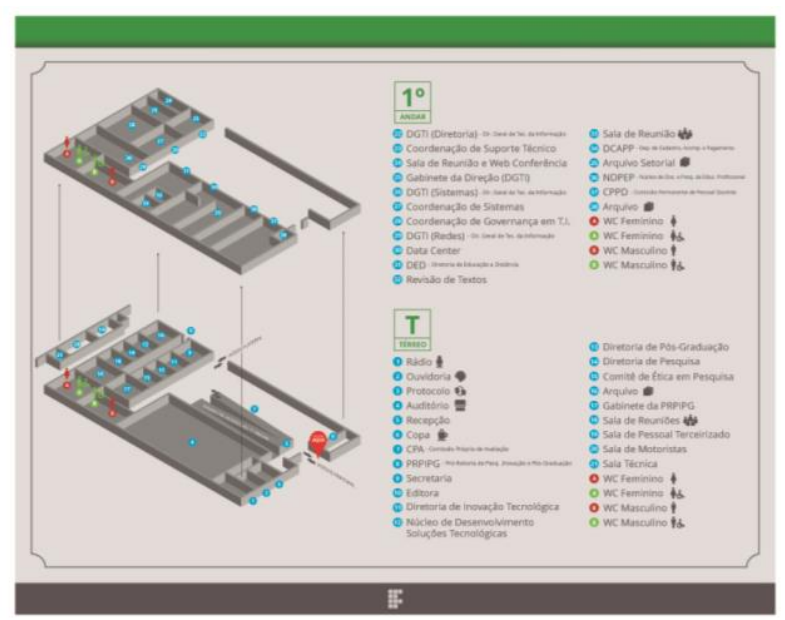

Figura 13 - Utilização dos esquemas tridimensionais nos diretórios da Casa Rosada.

\subsection{Estruturas de sinalização}

A tecnologia empregada nas estruturas de sinalização buscou aliar a durabilidade, resistência as intempéries, qualidade estética e a viabilidade de produção. Neste sentido, as estruturas internas foram confeccionadas em PVC expandido com detalhes em acrílico e as externas em chapas de
ACM, seguindo as mesmas cores. Os elementos textuais e pictográficos foram produzidos em vinil adesivo UV recortado e aplicados sobre as superfícies. Procurou-se utilizar de formas que não agredissem os usuários, evitando a exposição de cantos vivos e arestas cortantes.

Na última fase do projeto, o Pós-Projeto, foram desenvolvidos protótipos para teste no local e feito todo o acompanhamento do processo de produção e instalação.

Para definir a melhor localização de cada placa, foi realizado um estudo do campo visual para pessoas em pé, sentadas ou em cadeira de rodas, conforme a NBR 9050/15. Assim, as placas foram localizadas dentro desses limites que otimizam a percepção do olho humano (Figura 14).
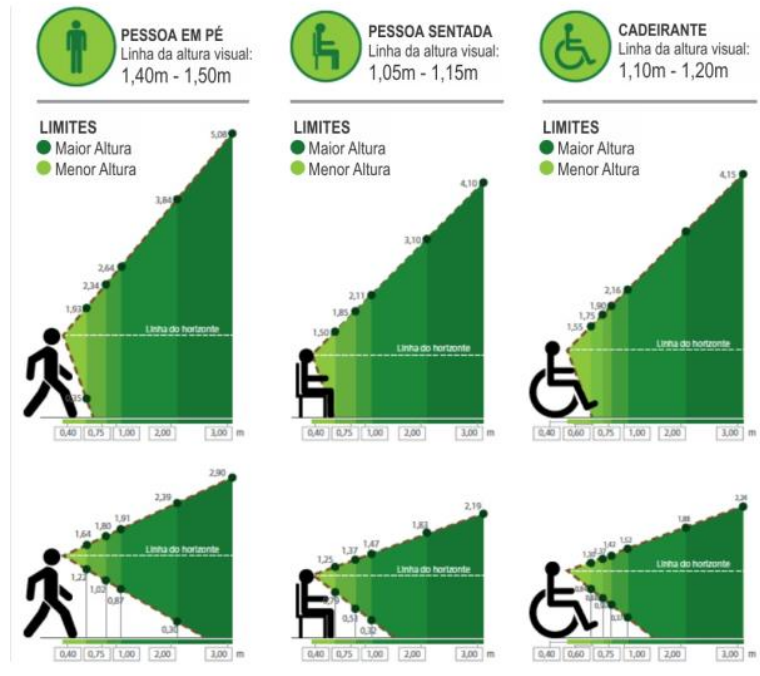

Figura 14 - Campo visual. Fonte: adaptado da ABNT NBR 9050/15 (2015, p.27).

As placas identificativas de ambientes foram instaladas nas paredes, fixadas com fita dupla face, ao lado das portas, a uma altura de $1,50 \mathrm{~m}$, favorecendo a legibilidade e a clareza da informação, e atendendo às pessoas com deficiências visuais, sentadas, em pé ou caminhando. Já as placas suspensas foram instaladas acima de $2,10 \mathrm{~m}$ do piso, evitando contato físico com os usuários, fixadas no teto com 


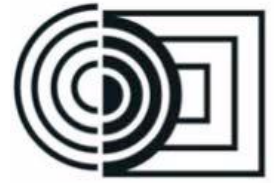

$16^{\circ}$

ERGODESIGN

USIHC CINAHPA $16^{\circ}$ Ergodesign - Congresso Internacional de Ergonomia e Usabilidade de Interfaces Humano Tecnológica: Produto, Informações Ambientes Construídos e Transporte

$16^{\circ}$ USIHC - Congresso Internacional de Ergonomia e Usabilidade de Interfaces Humano Computador

CINAHPA | 2017 - Congresso Internacional de Ambientes Hipermídia para Aprendizagem. tubos de alumínio.

Para se ter uma visão geral do projeto desenvolvido, seguem imagens de algumas das estruturas de sinalização criadas, já instaladas no local (Figuras 15, 16, 17, 18 e 19).

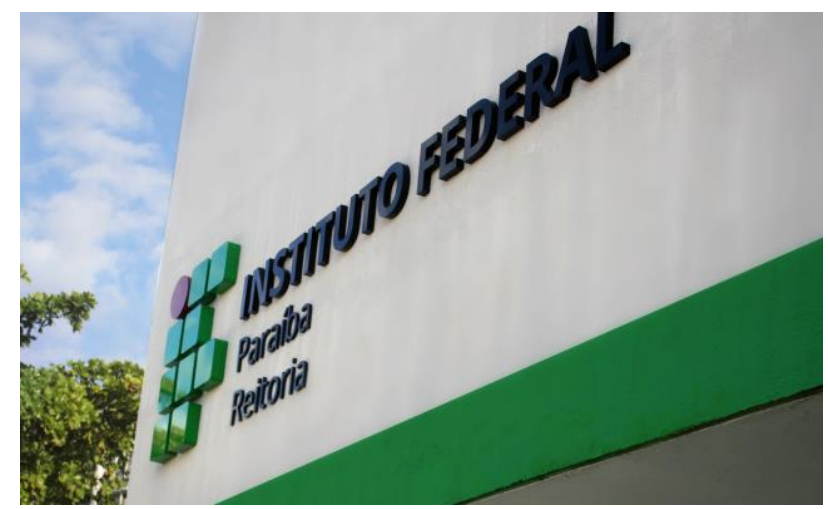

Figura 15 - Identificação da edificação em letra caixa.

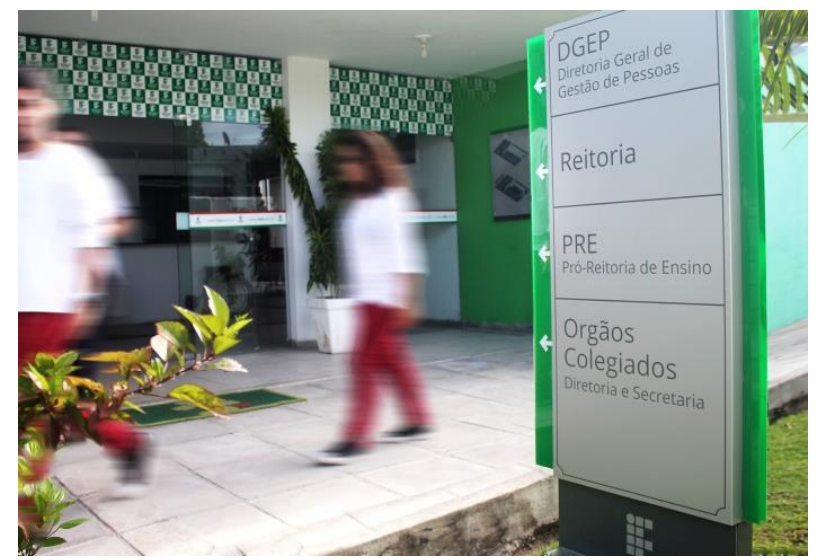

Figura 16 - Totem direcional.

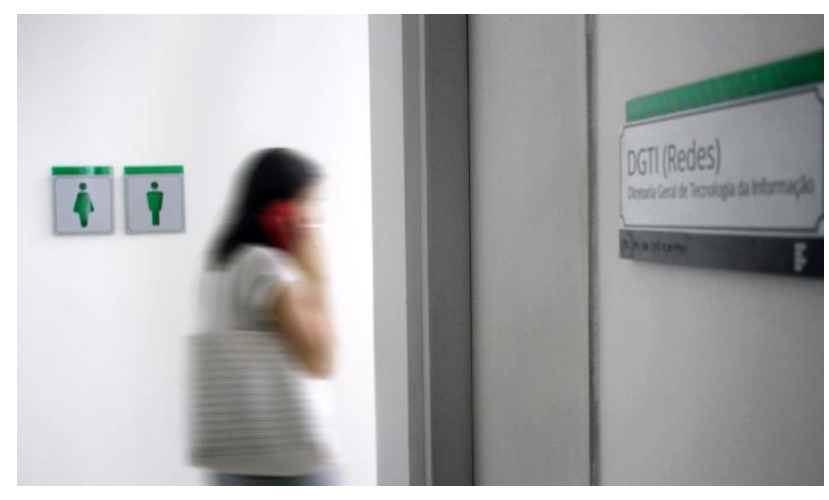

Figura 17 - Placa identificativa de banheiro e ambiente, instalada na parede ao lado das portas, fixadas a $1,50 \mathrm{~m}$

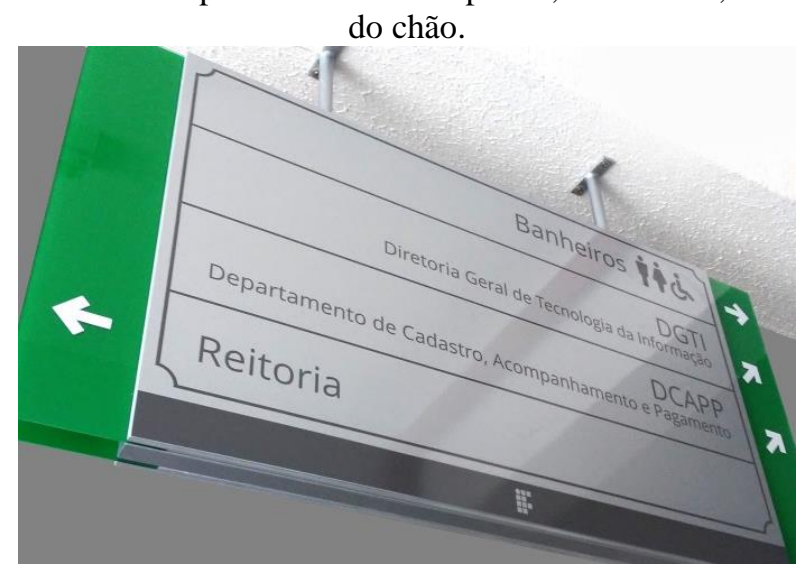

Figura 18 - Placa direcional suspensa.

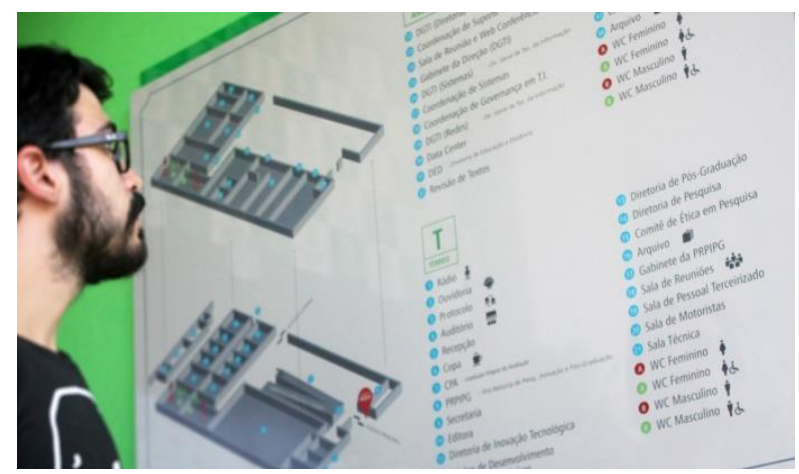

Figura 19 - Diretório instalado na entrada da Casa Rosada.

\section{Conclusão}

O desenvolvimento do sistema de sinalização procurou solucionar os problemas no IFPB decorrentes da precária sinalização existente. $\mathrm{O}$ método proposto por Calori (2007) se revelou como um processo capaz de reunir, analisar e definir as diretrizes das etapas do trabalho, facilitando assim a organização de todas as atividades realizadas. $\mathrm{O}$ desenvolvimento dos elementos de sinalização foi alcançado graças às pesquisas feitas que permitiram compreender as necessidades dos usuários e a dinâmica de funcionamento dos ambientes.

\section{Realização:}




\section{$16^{\circ}$ \\ ERGODESIGN USIHC CINAHPA}

Ao término do processo criativo foi possível chegar a uma solução equilibrada que valoriza a identidade do Instituto e acrescenta elementos acessíveis a todos os usuários e que serão de grande utilidade para a Instituição.

A diversidade de problemas a serem solucionados envolveu a conexão de conhecimentos de várias áreas como design gráfico, arquitetura, design de interiores e desenho industrial, reforçando a multidisciplinaridade do design que é fundamental para o aprendizado, a aquisição de novos conhecimentos e ampliação da experiência profissional.

\section{Bibliografia}

\section{ASSOCIAÇÃO BRASILEIRA DE NORMAS} TÉCNICAS. NBR 9050: Acessibilidade a edificações, mobiliário, espaços e equipamentos urbanos. 3. Ed. Rio de Janeiro, 2015.

BASTOS, Roberto Severo. Sinalização: a comunicação visual a serviço da identidade e dos ambientes. Porto Alegre: UniRitter Ed., 2004.

BERGER, Craig M. WAYFINDING. Designing and Implementing Graphic Navigational Systems. Switzerland: RotoVision SA, 2009.

\section{CALORI, Chris. Signage and Wayfinding}

design: Acomplete guide to creating environmental graphic design systems. New Jersey: John Wiley \& Sons, Inc, 2007.

D'AGOSTINI, Douglas e GOMES, Luiz Antônio Vidal de Negreiros. Design de Sinalização: planejamento, projeto \& desenho. Porto Alegre: Uniritter, 2011.

GIBSON, David. The Wayfinding Handbook. Chronicle Books, 2009.

GOMES Filho, João. Gestalt do Objeto: sistema de leitura visual da forma. São Paulo: Escrituras, $16^{\circ}$ Ergodesign - Congresso Internacional de Ergonomia e Usabilidade de Interfaces Humano Tecnológica: Produto, Informações Ambientes Construídos e Transporte

$16^{\circ}$ USIHC - Congresso Internacional de Ergonomia e Usabilidade de Interfaces Humano Computador

CINAHPA | 2017 - Congresso Internacional de Ambientes Hipermídia para Aprendizagem.

2000.

IIDA, Itiro. Ergonomia: projeto e produção. São Paulo: Edgard Blücher, 2005.

REDE FEDERAL DE EDUCAÇÃO PROFISSIONAL, CIENTÍFICA E TECNOLÓGICA. Manual de Aplicação da Marca. $3^{\text {a }}$ Edição. 2015. Brasil. Disponível em: <http://redefederal.mec.gov.br/images/pdf/manual. pdf >. Acesso em: 10 ago. 2016.

SMITSHUIJZEN, Edo. Signage Design Manual. Switzerland: Lars Müller Publishers, 2007. 